Penultimate draft of a paper forthcoming in The Journal of Ethics. Please cite the published version.

\title{
THE CONCLUSION OF PRACTICAL REASONING
}

\author{
John Brunero
}

ABSTRACT: According to the Aristotelian Thesis, the conclusion of practical reasoning is an action. Critics argue against it by pointing to cases in which some interference or inability prevents the production of action, yet in which that interference or inability doesn't impugn the success of an agent's reasoning. Some of those critics suggest instead that practical reasoning concludes in an intention, while others suggest it concludes in a belief with normative content, such as a belief about what one has conclusive, or sufficient, reason to do. In this paper, I argue that we should allow that practical reasoning could conclude in either an intention or a belief with normative content. I begin by developing an objection to the Aristotelian Thesis, showing how the objection will not also undermine the possibility of practical reasoning concluding in an intention or a belief. I then respond to an argument from Joseph Raz designed to exclude the possibility of intentions as conclusions of practical reasoning. Lastly, I show how the worry that belief isn't sufficiently "practical" to qualify as a conclusion of practical reasoning is misplaced.

According to the Aristotelian Thesis, the conclusion of practical reasoning is an action. Defenders of this thesis hold that it provides a way of distinguishing theoretical from practical reasoning: whereas theoretical reasoning concludes in a belief, practical reasoning concludes in an action. They will concede the possibility of theoretical reasoning about a practical subject matter - for instance, my reasoning to some belief about how I, or someone else, ought to act in a particular set of circumstances, perhaps even the very circumstances in which I now find myself. However, Aristotelians insist that such reasoning isn't, strictly speaking, practical reasoning if it doesn't issue in an action. Rather, it's merely theoretical reasoning about a practical subject matter.

Several philosophers, including Elizabeth Anscombe, have attributed the thesis to Aristotle, and there are passages in Aristotle's work which suggest that he would endorse it. ${ }^{1}$ But I'm going to leave aside the question of how to interpret Aristotle. There are enough contemporary defenders of the Aristotelian Thesis -- including Philip Clark, Sergio Tenenbaum, Christine Korsgaard, Jonathan Dancy, and Patricio Fernandez - to make it an interesting topic of discussion in its own right. ${ }^{2}$

\footnotetext{
${ }^{1}$ See Anscombe 1957, \$33. The relevant passages from Aristotle include De Motu Animalium 701a11-22, and Nicomachean Ethics 1139a 21-22 and 1147a 26-31. In this last passage, Aristotle writes: "And in the cases where these two beliefs [one universal, one about particulars] result in one belief, it is necessary, in one case, for the soul to affirm what has been concluded, but, in the case of beliefs about production, to act at once on what has been concluded. If, for instance, everything sweet must be tasted, and this, some one particular thing, is sweet, it is necessary for someone who is able and unhindered also to act on this at the same time" (translation from Terence Irwin; Aristotle 1999). For further discussion of Aristotle's views, see Charles 1984, Audi 2006, 13-36, and Clark 2001, 485-9.

2 See Clark 2001, Tenenbaum 2007, Korsgaard 2009, esp. 124-124, Dancy 2014, 2018, and Fernandez 2016. Also, Eric Wiland (2013), while not directly defending the Aristotelian Thesis, argues that the thesis becomes more plausible if we allow actions to be among the premises of practical reasoning. The debate over the conclusion of practical reasoning is separate from the debate over the aim of practical reasoning, which will not be our concern here. See, for instance, Velleman 2000 , McHugh and Way 2018, Silverstein 2017, and Vogler 2002, for accounts of the aim of practical reasoning.
} 
Penultimate draft of a paper forthcoming in The Journal of Ethics. Please cite the published version.

The Aristotelian Thesis is controversial. Critics argue against it by pointing to cases in which some interference or inability prevents the production of action, yet in which that interference or inability doesn't impugn the success of an agent's reasoning. Suppose it's getting too dark to read, and you intend to turn on the light, which you know you must do by flipping the switch. You intend to flip the switch, but due to a sudden paralysis, you're unable to move your arm. ${ }^{3}$ Your reasoning doesn't result in an action, but it doesn't thereby seem to be incomplete or defective; indeed, it seems you've reasoned impeccably from your intention to read, to an intention to turn on the light, to an intention to flip the switch. Your sudden inability to move your arm isn't a defect in your reasoning.

Consideration of such cases has led some philosophers, such as John Broome and Sarah Paul, to locate the conclusion of practical reasoning further back in the mind, specifically in the formation of an intention. ${ }^{4}$ In our example, they would argue, your reasoning concludes when you form the intention to flip the switch. Your flipping the switch - in the case where there's no inability or interference - occurs after your reasoning has already concluded.

Yet other philosophers, such as Robert Audi and Joseph Raz, while agreeing with critics of the Aristotelian Thesis, think that we need to push the conclusion of practical reasoning even further back in the mind: they hold that practical reasoning concludes in a belief or judgment with normative content, such as a belief about what one has conclusive, or sufficient, reason to do. ${ }^{5}$ In our example, the conclusion of your practical reasoning might be your belief that you have conclusive reason to flip the switch. Neither your forming the intention to flip the switch, nor your flipping it, should be considered part of your practical reasoning; both occur after your reasoning has already concluded. If

${ }^{3}$ Such examples involving paralysis are common. See, for instance, Shah (2008, 4), Paul (2013, 300), and Broome (2013, 250). As the quotation from Aristotle in fn. 1 above - specifically, his inclusion of the clause "who is able and unhindered" - indicates, Aristotle was aware of the possibility of action failing to result from inability or interference. We'll discuss below the significance of such cases for the debate over the conclusion of practical reasoning. I'm assuming in this case that you are not aware of, nor do you have evidence of, the paralysis in your arm, and it comes as a surprise to you when you attempt to act. Not only need there be no failure of practical reasoning here, there also need be no failure of practical rationality. It's true that intending to flip the switch is in fact an ineffective means to your end, which you in fact cannot achieve. But on the standard understanding of instrumental rationality (see Brunero 2020, Ch.1, and the citations therein) that doesn't suffice for instrumental irrationality.

${ }^{4}$ See Broome 2002, 2013, and Paul 2013. Although Paul sets up the debate such that she is defending the intentions-asconclusions view against the Aristotelian Thesis, she notes (p. 288) that her discussion would generalize to cover other attitudes, such as beliefs about what one ought to do, as possible conclusions of practical reasoning.

${ }^{5}$ See Raz 2011a, 2011b, 2015, and Audi 2006, especially Chapter 4. Another way to hold that beliefs are the conclusions of practical reasoning would be to supplement an intentions-as-conclusions view with a strong cognitivism about intention, according to which intentions are a kind of belief about what one will do. (See, for instance, Velleman 1989, and, more recently, Schwenkler and Marušić 2018). Raz and Audi do not proceed this way. In this paper, I'm going to remain neutral on the question of whether strong cognitivism about intention is correct. As we'll see shortly, this paper will defend the Disjunctive View that practical reasoning could conclude in either a belief about what one has conclusive or sufficient reason to do, or an intention. But if strong cognitivism were true, then I would also allow that practical reasoning could conclude in a belief about what one will do. 
this view is correct, then perhaps we shouldn't think of practical reasoning as a special kind of reasoning, distinct from theoretical reasoning in virtue of its conclusion. As Raz puts it, "the conclusions of practical reasoning, like the conclusions of all reasoning, are beliefs." ${ }^{\prime \prime}$ (Of course, practical reasoning is still distinct from theoretical reasoning in virtue of its subject matter: practical reasoning is reasoning about practical matters, and so will conclude in a belief about what one has conclusive (or sufficient) reason to do. ${ }^{7}$ But it isn't distinct in virtue of its concluding attitude.)

These three views about the conclusion of practical reasoning - that it concludes in an action, in an intention, and in a belief - are the standard options in the debate over the conclusion of practical reasoning, with philosophers usually defending one of these three views. Indeed, we can see the debate set up this way at least as far back as the introduction to a 1978 volume on practical reasoning. ${ }^{8}$ However, the standard menu of options could lead us to overlook the possibility of more permissive, disjunctive views. In particular, the central thesis of this paper is that we should take seriously the view that practical reasoning could conclude in either an intention or a belief. In this paper, I'll defend this view, which I'll call "The Disjunctive View," against what I take to be the most important challenges that could be put to it.

Of course, there are going to be challenges from all sides. Aristotelians will argue that the view doesn't allow for practical reasoning to extend far enough. So, I'll start by developing an objection ( $(\mathbb{1})$ to the Aristotelian Thesis. There's a common worry that objections to the Aristotelian Thesis will over-extend to also undermine the view that practical reasoning can conclude in an intention. So, I'll take care to show that my case against the Aristotelian Thesis doesn't prove too much.

I'll then (\$2) consider an important, recent argument from Joseph Raz, designed to "exclude the possibility of intentions as conclusions of reasoning." ' I'll argue that Raz's argument doesn't succeed, but that its failure contains important lessons for how we should understand both practical and theoretical reasoning. Lastly, I consider (\$3) some objections from the other side, from those who wish to exclude the possibility of beliefs as conclusions of practical reasoning on the grounds that beliefs are too far removed from decision and action to count as genuinely "practical" conclusions.

\footnotetext{
${ }^{6}$ Raz, 2011a, 104.

${ }^{7}$ Raz 2011b, 129. Reasoning about what one's past self ought to have done, or about what someone else ought to do, would also have a practical subject matter. Raz (2011b, 135-136) worries that the intentions-as-conclusions theorist faces a difficulty here, since reasoning about what one ought to have done yesterday might not differ all that much from reasoning about what to do tomorrow, but only the latter could count as genuinely practical on that view.

${ }^{8}$ Raz 1978, 5.

${ }^{9}$ Raz 2015, 160.
} 
I'll argue that if we look at the practical role of concluding intentions - that is, their role in guiding further planning and choice, leading to action - we'll see that beliefs are sometimes able to play that very same role, and so such considerations don't provide principled grounds for disallowing beliefs as possible conclusions of genuinely practical reasoning. My hope is that the arguments of this paper, taken together, will provide a good prima facie case for the Disjunctive View.

\section{\$1. On Actions as Conclusions: Completed Reasoning}

It's worth noting at the start that the debate over the conclusion of practical reasoning is a normative one: the conclusion of practical reasoning is the appropriate or proper termination of a line of reasoning. No one doubts that there are ways in which your reasoning might cease - perhaps you are interrupted by some emergency, or perhaps you suddenly die - and that there is some sense in which your reasoning has here "concluded," namely the sense in which it has stopped. But that's not the sense of "conclusion" at issue in this debate. ${ }^{10}$ Rather, we're also inclined to say that these interruptions prevented you from "concluding" your reasoning in the sense that they prevented your reasoning from reaching its appropriate termination point, and the debate is about what that appropriate termination point is.

The example I mentioned at the start - the case in which you fail to flip the switch due to a sudden paralysis in your arm - presents a difficulty for the Aristotelian Thesis. Intuitively, there is nothing defective or incomplete about your reasoning. (We can of course imagine some interference or inability further upstream - perhaps instead of a sudden paralysis in your arm, you suffer from some sudden mental block that prevents you from even forming the intention to flip the switch. However, it doesn't seem implausible to say that in the case of the mental block there is something defective or incomplete about your reasoning. ${ }^{11}$ ) Here's how John Broome puts the point against the Aristotelian Thesis:

\footnotetext{
${ }^{10}$ Dancy 2014, 3-4.

${ }_{11}$ Dancy $(2014,13-15)$ correctly observes that, just as in the paralysis case, the case of the mental block need not involve any rational fault on the part of the agent. Perhaps both the paralysis and mental block are due to the interference of some malicious, external manipulator, in which case we wouldn't fault the agent at all. But it would be wrong to conclude from this there's something amiss with using the paralysis case to critique the Aristotelian Thesis. The point is that in the paralysis case, there isn't, intuitively, any problem with the agent's reasoning, while in the mental block case, there is, intuitively, a problem with the agent's reasoning - even though it could be inappropriate to blame the agents for the problems in both cases.
} 
Aristotle took practical reasoning to be reasoning that concludes in an action. But an action

- at least a physical one - requires more than reasoning ability; it requires physical ability too.

Intending to act is as close to acting as reasoning alone can get us. ${ }^{12}$

In a case where you lack the relevant physical ability, like when your arm is paralyzed, there isn't anything defective or incomplete about your reasoning, and so it's better if we understand your reasoning as concluding earlier on, in the formation of an intention. Let's call this objection "the Completed Reasoning Objection" since the main idea is that your reasoning, intuitively, is already completed prior to action.

The paralysis case is often appealed to since it's clear that there's no (physical) action that occurs. But other more ordinary cases could illustrate the same point. Suppose I want a caffeinated beverage this afternoon, and I think through the pros and cons of various options, ultimately settling on a decision to buy a coffee. However, suppose that on the way to the campus coffee shop, a friend approaches me to discuss something urgent, or I get distracted by the new arrivals in the campus bookshop, and I never end up buying a coffee. In these cases, while I might be in the process of performing some action (for instance, walking to the coffee shop), the interruption or distraction prevents me from performing the action supported by my reasoning (getting a coffee). But, again, it seems that my reasoning has already concluded by this point.

\section{\1.1 Is the Objection Too Strong?}

Some philosophers have argued that the Completed Reasoning Objection is stronger than its proponents realize, since it also targets the intentions-as-conclusions view. Joseph Raz observes that a failure to form an intention need not be a failure of reasoning, and so this same kind of argument could be employed against the intentions-as-conclusions view. Raz writes:

But this argument shows that reasoning cannot take us as far as intention either. Weakness of will is paradigmatically failure to form intentions when our best judgment, possibly based on impeccable reasoning, tells us that we should. So understood, Broome's argument refutes his own view that intentions can be conclusions of practical reasoning. ${ }^{13}$

In support of the claim that weakness of will need not involve incomplete or defective reasoning, Raz observes that it would be odd to approach the akratic agent and ask, "Why did you not complete your

\footnotetext{
12 Broome 2002, 85.

13 Raz 2011b, 132.
} 
reasoning?" or "Why did you interrupt your reasoning midway?"14 It seems that he did complete his reasoning, but failed to form the relevant intention because of a defect in his willpower. ${ }^{15}$

Jonathan Dancy pushes the point even further, arguing that the objection also threatens to rule out the view that theoretical reasoning concludes in a belief. ${ }^{16}$ If we think of cases of epistemic akrasia, in which someone believes he ought to believe that P but doesn't believe that P, it doesn't seem that the problem is that there's more reasoning left to do. Rather, the epistemically akratic believer just needs to come to believe what, by his lights, he should believe. So, the objection would also show that beliefs cannot be conclusions of theoretical reasoning (and likewise, that beliefs with normative contents cannot be conclusions of practical reasoning). The objection is, he alleges, too strong.

I'm not convinced by Raz's and Dancy's replies. Both appeal to cases in which an agent proceeds from some normative belief to the formation of a specific attitude. And while forming those attitudes might involve compliance with some rational requirement, I agree that it's doubtful that proceeding this way involves reasoning. However, there are other cases where the reasoning would be incomplete without the formation of an intention or a belief. Suppose we consider a case of instrumental reasoning involving means believed to be necessary:

Intention I shall E.

Belief I shall E only if I M.

Intention I shall M.

(I'll here follow the familiar convention of listing the attitudes in the left-hand column and their contents in the right-hand column, drawing a line to separate the "premise-attitudes" from the "conclusion-attitudes" of the reasoning.) This reasoning involves more than the mere discovery of means necessary for E-ing. Such a discovery, isn't, by itself, a piece of practical reasoning. ${ }^{17}$ But when someone puts an instrumental belief together with an intention to $\mathrm{E}$, and forms an intention to $\mathrm{M}$ on that basis, he is engaged in instrumental reasoning, which is a paradigmatic form of practical

\footnotetext{
${ }^{14}$ Raz 2011b, 133. See also Raz 2015, 151-152: "After all I cannot follow up by asking you: 'when will you finish your reasoning?'. It is clear that it is over. Only the problem of resolve remains."

15 At one point, Dancy $(2018,132)$ replies to Raz's argument by accepting the allegedly counterintuitive conclusion that one's reasoning is here incomplete, while trying to remove the counterintuitiveness by also observing that there is no rational requirement to complete one's reasoning, and so interrupted reasoning need not involve any irrationality. I think this observation is correct, but it misses the point. Raz's point is that it's implausible to think of akrasia as involving incomplete reasoning to begin with. Nothing hinges on the further question of whether such incomplete reasoning involves "rational fault."

16 Dancy 2018, 104.

17 A point made by Williams 1981, 104, among others.
} 
reasoning. ${ }^{18}$ Of course, we should allow for the possibility that someone with this intention and instrumental belief might learn that E-ing is not worth doing, perhaps because M-ing would be too costly, and, on that basis, abandon the intention to E instead, without being irrational in doing so. (A similar point holds for theoretical reasoning: it's possible for someone who believes that $\mathrm{P}$ and believes that $\mathrm{P} \rightarrow \mathrm{Q}$ to proceed to revise one of these two beliefs instead of coming to believe that Q. Perhaps he comes across good evidence that $\sim Q$ and revises on the basis of that evidence.) Nonetheless, this is clearly a line of good instrumental reasoning, and if someone fails to form the intention to M only because of some interruption or distraction, we have no trouble holding that the reasoning here failed to reach its conclusion.

We could also present a similar reply to Dancy's extension of Raz's strategy. If the only way theoretical reasoning could conclude in a belief were by going from a belief that one ought to believe that $\mathrm{P}$ to the belief that $\mathrm{P}$, then it could easily seem as though all the relevant reasoning has concluded before one forms the belief. But there are other cases of reasoning leading to a belief that are much less problematic. Consider ordinary modus ponens reasoning:

$\begin{array}{ll}\text { Belief } & \mathrm{P} \\ \text { Belief } & \mathrm{P} \rightarrow \mathrm{Q} \\ \text { Belief } & \mathrm{Q}\end{array}$

If someone were to start reasoning and some intervention were to prevent the formation of the belief that Q, one's reasoning would here be incomplete.

One might object that my reasoning here is enthymematic, and that a full specification of my instrumental reasoning, making explicit the hidden premises, would look like this:

Intention I shall E.

Belief I shall E only if I M.

Belief I ought to intend to M.

Intention I shall $\mathrm{M}$.

Likewise, for theoretical reasoning:

$\begin{array}{ll}\text { Belief } & \mathrm{P} \\ \text { Belief } & \mathrm{P} \rightarrow \mathrm{Q} \\ \text { Belief } & \mathrm{I} \text { ought to believe that } \mathrm{Q} . \\ \text { Belief } & \mathrm{Q}\end{array}$

18 Broome (2013, 250), for instance, holds it to be a "central case of practical reasoning." 
These would be what John Broome calls "higher-order accounts" of reasoning, since they hold that higher-order beliefs, specifically beliefs about the attitudes one ought to have, figure among the premises of the reasoning. And one might now press the Raz/Dancy objection once more: it seems that all of my reasoning is over and done with before I form the concluding intention (in the instrumental case) or the concluding belief (in the theoretical case).

There are, however, several problems with such accounts of reasoning. For one thing, they make ordinary instrumental and modus ponens reasoning overly sophisticated by requiring that one grasp normative concepts, like the concept of ought, in order to engage in such reasoning. ${ }^{19}$ For another, surely such normative beliefs aren't necessary for good reasoning. For instance, the person who believes that $\mathrm{P}$ and believes that $\mathrm{P} \rightarrow \mathrm{Q}$ already has a good enough basis for concluding that $\mathrm{Q}$. Additionally, there are clear cases where one engages in the relevant reasoning without having such higher-order beliefs. For instance, there are cases of instrumental reasoning which display what R. Jay Wallace, following Aristotle, calls "cleverness" in the pursuit of an end one believes one ought not pursue. ${ }^{20}$ For instance, I may think I ought not go out tonight, but intend to go to a party, believe that to get there I must drive up $27^{\text {th }}$ street, and, on the basis of these two attitudes, form an intention to drive up $27^{\text {th }}$ street, all the while believing that I ought not go out tonight and ought not drive up $27^{\text {th }}$ street. And, if epistemic akrasia is possible, we could make a similar point about modus ponens reasoning. Consider the familiar example of the father who just can't bring himself to believe that his son is guilty of some terrible crime, despite recognizing the overwhelming evidence for it. The father might believe that Sonny didn't do it, and that if Sonny didn't do it, someone else did, and, on the basis of these beliefs, come to conclude that someone else did it, all the while believing that he ought to believe that Sonny did in fact commit the crime. ${ }^{21}$

In summary, these higher-order accounts of instrumental and modus ponens reasoning are problematic in several ways. But the lower-order accounts - that is, the lines of reasoning as we initially presented them - show the possibility of reasoning concluding in an intention and reasoning concluding in a belief. And if some interruption or interference were to prevent the formation of the concluding attitude, we'd be inclined to think that the reasoning failed to reach its conclusion. We can grant Raz the point that proceeding from a belief that one ought to $\phi$ to an intention to $\phi$ doesn't

\footnotetext{
19 See Broome 2013, 228-229.

20 Wallace 2001, 1.

21 As we noted earlier, the lower-order patterns of (instrumental and modus ponens) reasoning don't require higher-order beliefs. However, there may be forms of reasoning involving higher-order beliefs that are similar to, but distinct from, the lower-order patterns of reasoning, such as reasoning about the transmission of normativity from ends to necessary means.
} 
seem to involve reasoning, and the point that in cases where the intention to $\phi$ isn't formed, it doesn't seem right to say that the agent's reasoning was interrupted midway. But that's not the only possibility available for reasoning to a concluding intention, as our example of instrumental reasoning shows. (And we can make a similar response to Dancy, conceding that proceeding from a belief that one ought to believe that $\mathrm{P}$ to believing that $\mathrm{P}$ doesn't seem to involve reasoning. But that's not the only possibility available for reasoning to a concluding belief, as our example of modus ponens reasoning shows.) The problem for the Aristotelian Thesis, however, is that in no case does an interruption that prevents the action from occurring amount to an interruption in the activity of reasoning; rather, it seems that our reasoning is over and done with prior to the "concluding action" being performed.

We can also offer an explanation of why an interruption that prevents action from occurring doesn't amount to incomplete or defective reasoning: one of the central functions of intentions is to allow completed reasoning to extend its influence to action at a later time. Consider this passage from the opening chapter of Michael Bratman's Intentions, Plans, and Practical Reason, where Bratman argues that intentions enable deliberation to extend its influence beyond the present:

We are rational agents, to some extent. For us this means in part that deliberation and, more generally, rational reflection help shape what we do. If, however, our actions were influenced only by deliberation at the time of action, the influence of such deliberation would be rather minimal. This is so because deliberation requires time and other limited resources, and there is an obvious limit to the extent to which one may successfully deliberate at the time of action. So we need ways to allow deliberation and rational reflection to influence action beyond the present. $^{22}$

Intentions meet our "general need" to extend the influence of deliberation over time. They do this, in part, by closing off deliberation. For instance, I can decide on Monday where I'll eat on Friday, freeing me up to think about other things during the week, and allowing me to take this for granted in my further planning. (Of course, we don't want to overstate the extent to which intentions close off deliberation. I may revisit the question of where to eat on Friday, especially if new information comes to light. Perhaps I learn that the restaurant has raised its prices significantly, and so I revisit the question of where to eat. But we can at least say that once I decide where I'm going to eat, I'll treat that question as being provisionally closed.) In taking this for granted in further planning, I might have to later engage in further reasoning (perhaps reasoning about the best way to drive to the restaurant) and further decisions (perhaps choosing one among many equally good parking spots in

\footnotetext{
22 Bratman 1987, 2.
} 
Penultimate draft of a paper forthcoming in The Journal of Ethics. Please cite the published version.

the restaurant parking lot). ${ }^{23}$ But I can now treat the question of where to eat as provisionally closed, freeing me up to deliberate about other matters. If one of the central functions of intentions is to allow completed reasoning to exert its influence at a later time, it should come as no surprise that an interruption between intention and action doesn't involve incomplete or defective reasoning. ${ }^{24}$

I've been largely focusing here on what are often called "prospective intentions," or "prior intentions," as opposed to intentions-in-action. ${ }^{25}$ There are large and difficult questions about how to understand both prospective intentions and intentions-in-action, and how they are related both to one another and to intentional action, and I hope to avoid these questions in this paper. ${ }^{26}$ It's plausible that a prospective intention becomes an intention-in-action when the relevant time for action comes. To borrow McDowell's example, my prospective intention to cross the street when the light turns becomes an intention-in-action (with the content "I am crossing the street", in McDowell's view), when the light turns. ${ }^{27}$ It's also plausible that practical reasoning could conclude directly in an intentionin-action, (not via the formulation of a prospective intention), perhaps in cases where immediate action is called for. (Most examples of practical reasoning in the literature, like my example of instrumental reasoning above, involve a concluding prospective intention. But we may also want to allow for the possibility of a concluding intention-in-action.) In such cases, the Bratmanian explanation I presented above, according to which intentions save deliberative resources by allowing deliberation to extend its influence across time, would be inapplicable, since deliberation would be exerting its influence at the moment. But at least in cases of prospective intention, we have available an explanation of why an interruption that prevents intention from issuing in action doesn't involve interrupted or incomplete reasoning: the function of such intentions is to allow completed reasoning to exert its influence at a later time.

\footnotetext{
23 I'll return to the practical role of concluding intentions in $\$ 3$. It would be implausible to think that reasoning extends through all of the particular decisions made prior to action, and through all of the particular ways in which an action might be performed. When there are 10 equally good parking spots and I must choose one, and there are very many particular ways I could pull my car into the chosen parking spot, or position my hands on the steering wheel as I do so, it seems to be just a matter, as Sarah Paul $(2013,296)$ puts it, of "plumping for indifferent, adequate ways of getting it done" as opposed to reasoning. On the other hand, there are cases in which it would be inappropriate to plump for one particular option. To borrow an example from Anton Ford (2016, 150-153), suppose I reason from an intention to disarm the bomb to an intention to snip some wire, but I don't yet know whether snipping this particular wire will disarm or detonate the bomb. Plumping would be inappropriate here. As Ford describes the case, "ignorance of particulars prevents practical reasoning from issuing in knowledge of what to do" $(2016,151)$. See also footnote 60 below.

24 It's compatible with this thought that there can be failures in the execution of an intention, including failures that involve agential irrationality. But such failures need not be failures of reasoning. Sarah Paul $(2013,298)$ makes a point along these lines in response to Sergio Tenenbaum's (2007) defense of the Aristotelian Thesis.

25 See, for instance, Searle 2001, 44-45.

26 See Setiya 2018 for a helpful overview.

27 McDowell 2010, 2011. See also Searle 2001, 45.
} 
In allowing for practical reasoning to conclude in an intention-in-action, we wouldn't thereby be giving up the game to the Aristotelian, so long as we hold that the relevant intention is insufficient for action. It's standardly thought that an intention-in-action is one component of intentional action, perhaps one which helps distinguish intentional action from mere behavior, but it's not the only component: an action - at least a physical action - also requires bodily movement, as Broome points out in the passage above. ${ }^{28}$ And the paralysis case, which we used above to motivate the Completed Reasoning Objection, is often used to demonstrate this possibility. ${ }^{29}$ It shows that something more would be needed for action. And, again, the worry for the Aristotelian Thesis is that when one fails to act only because one is paralyzed, one's reasoning isn't thereby incomplete or defective.

\section{$\int 1.2$ Dancy's Focalism}

Let's turn to another response to the Completed Reasoning Objection, recently advanced by Jonathan Dancy in his book Practical Shape. On Dancy's theory of reasoning, reasoning is an attempt to discover which response is most favored by the relevant reasons, and to respond in the way favored by those reasons. As he puts it:

My general picture of reasoning sees it as a process in which we work from a detailed conception of the situation that confronts us to a response that is of the sort most favored by the relevant considerations, taken as a whole. That response will be action (in practical reasoning) or belief (in theoretical reasoning). ${ }^{30}$

In theoretical reasoning, one looks to reasons for believing that $\mathrm{P}$, and if those reasons conclusively favor believing that $\mathrm{P}$, one responds by believing that $\mathrm{P}$. And in practical reasoning, one looks to

28 See also Searle 2001, 45.

${ }^{29}$ To give one illustration of the use of a paralysis case to demonstrate this possibility, we could look to Robert Brandom's account of intentions-in-action. Brandom (1994, 257-259) takes intentions-in-action to be what Sellars called "volitions" and he quotes Sellars's $(1966,110)$ description of a prospective intention becoming an intention-in-action: A simple case of the relation of intending to volition can be illustrated by considering Jones, who has formed the intention of raising his hand in ten minutes. Suppose that no alternative course of action recommends itself to him. Then we may picture the situation as follows:

I shall raise my hand in ten minutes.

$\cdots$

I shall raise my hand in nine minutes.

...

I shall raise my hand now.

(which culminates in action, if Jones happens not to be paralyzed.)

I mention this passage only to illustrate the use of a paralysis case for this purpose, and not to endorse any particular account of intentions-in-action.

${ }^{30}$ Dancy 2018, 8. 
practical reasons - that is, reasons for action - and if those reasons favor $\phi$-ing, one responds by $\phi$ ing. (It's of course true that reasons for action are usually also reasons to intend to act. For instance, the nice weather is both a reason for me to take a walk and a reason for me to intend to take a walk. But it is a reason to intend to take a walk because it is a reason to take a walk. ${ }^{31}$ In other words, reasons for action are "primary.")

Dancy's treatment of the Completed Reasoning Objection employs his "focalist" approach to reasoning. Rather than search for necessary and sufficient conditions for reasoning, Dancy aims to select central, "focal" cases of reasoning, and then explain peripheral cases by reference to the central cases. As he puts it, "the [focalist] programme amounts to saying: these things are practical reasoning, and anything sufficiently relevantly similar to them is practical reasoning too." 32 He tells us that "focalism enables us to avoid objections that derive from the fact that some instances of practical reasoning are not completed, in the sense that the relevant action does not occur for one reason or another." 33 The central cases of practical reasoning conclude in action. The cases where some interruption prevents the action from occurring (as when one is "distracted, forgetful, prevented, or unaware the moment has come") are similar enough to the central cases to allow them to count as reasoning too. ${ }^{34}$ We can also allow that such cases involve some defect or imperfection, not present in the central cases. But an imperfect or defective case of practical reasoning still counts as a case of practical reasoning. ${ }^{35}$

However, opponents of Aristotelianism will take issue with Dancy's claim that these are imperfect cases of reasoning. They need not deny that something goes wrong in cases where some interruption prevents the action from occurring, and so they could concede there is some imperfection or defect exhibited in these cases, perhaps best described as a defect in the execution of an intention. But, they would ask, why should we say these are defective cases of practical reasoning?

Moreover, the focalist reply seems to just move the bump in the rug, since critics of Aristotelianism will now challenge the description of the central cases: they'll argue that those cases will need to be more narrowly tailored, since they include reasoning but also include something else besides it. As Robert Audi, who is Dancy's primary target in these passages, points out, the problem with Aristotelianism is that "it makes practical reasoning a hybrid of what is, intuitively, reasoning,

\footnotetext{
31 Dancy 2018, 4.

32 Dancy 2018, 6.

33 Dancy 2018, 6-7.

${ }^{34}$ Dancy 2018, 104.

35 Dancy 2018, 104.
} 
and, on the other hand, action based on it." 36 What the Completed Reasoning Objection aims to do is to bring out the hybrid nature of the "central cases" by looking to cases where reasoning is completed without action resulting. And so critics of Aristotelianism, like Audi, would now challenge Dancy's description of the central cases, suggesting that they be more narrowly tailored. ${ }^{37}$ Those cases do include what is intuitively reasoning, but also include something else besides it. ${ }^{38}$

There's an additional worry about Dancy's reply: if we embrace the focalist program for practical reasoning, it now becomes difficult to draw the distinction between acting in light of practical reasoning and acting for reasons. Dancy sees the need to draw this distinction, recognizing that not all cases of acting for reasons involve acting in light of practical reasoning. He provides an example: when I get off the bus, I do so for a reason (it's my stop), but I may do this without reasoning about it in any way. It might just be a matter of habit. ${ }^{39}$ As Dancy sees it, the difference between acting for a reason and acting in light of practical reasoning "lies in the complexity of what one is responding to." ${ }^{40}$ I doubt this is the right way to draw the distinction Dancy is aiming to draw. Suppose we modify the bus example so as to provide the needed complexity in the considerations to which I'm responding. Suppose there are two bus stops near my office, one of which is very close, the other of which is a more pleasant walk, but the weather is bad today, which makes the pleasantness of the walk less weighty of a reason than it usually is. The "practical shape" of the situation, to use Dancy's phrase,

${ }^{36}$ Audi 2006, 90-91. To be clear, I'm not taking Audi's intuitions here to constitute an independent argument against the Aristotelian Thesis. The idea, rather, is that Dancy's focalism won't have much dialectical force against critics of Aristotelianism, like Audi, since those who share Audi's intuitions would simply reframe their objection in the way I suggest in the text below.

37 There is a way of construing the Completed Reasoning Objection so that Dancy's focalism would give a good reply. Suppose we thought the objection was merely that the "interruption" cases (in which one fails to act because of distraction or interference of some sort) show that the action isn't a necessary component of practical reasoning. But, the objection goes, Aristotelians think that it is a necessary component, and so they're mistaken. Dancy's focalism gives the Aristotelian a way out: the Aristotelian can agree that it's not a necessary condition since such cases count as cases of reasoning given their similarity to the central cases. But the Objection also shows that the central cases are, as Audi puts it, hybrids of what is intuitively reasoning and action based on it. And it's unclear how Dancy's focalism has the resources to respond to this concern.

${ }^{38}$ Consider a somewhat silly analogy: suppose I'm watching the Post-Game Show, to the annoyance of my spouse, to whom I made a promise to help out at the conclusion of the game. I argue that the game hasn't concluded. She disagrees, holding that the game concluded when the referee blew the final whistle. She points out, in support of her view, that there can be football games without a Post-Game Show. I respond, "I agree. Those are imperfect instances of football games, but given their similarity to my focal cases, I'll allow them to count as football games, even though they lack a Post-Game Show." She would likely reply, "No. You're missing my point. In selecting your central cases, you're casting too wide a net, including what is intuitively the football game, and something else besides it." (I intend the analogy to illustrate the relevant dialectic, as I see it, not to suggest that Aristotelianism is no more plausible than my peculiar views about football games.)

${ }^{39}$ Dancy 2018, 10-11.

${ }^{40}$ Dancy 2018, 11. As he puts it elsewhere, "in reasoning one moves from the considerations adduced, considerations of sufficient complexity for what is going on not just to be acting for (or more generally responding to) a reason, to whatever sort of response is (as we take it) most favored by those considerations, taken together." (5, emphasis added). 
is now more complex, since there are reasons on both sides, and a partial undercutting defeater to one of those reasons. (The closeness is a reason to get off at the first stop; the pleasant walk is a reason to get off at the second; but this reason is less strong than it otherwise would be, given the bad weather.) But am I now reasoning? Not necessarily. I might, just out of habit, get off at the first stop when the weather is bad, without giving the matter a second thought. ${ }^{41}$ It seems that to be reasoning about where to get off, I must also be thinking through, or in some way engaging with, the complex structure of the normative situation. In any case, let's put that concern aside. The worry here is that the focalist approach - according to which we say "these things are practical reasoning, and anything sufficiently relevantly similar to them is practical reasoning too" - would lead us to conclude that Dancy's bus stop example counts as practical reasoning too, given its similarity to my more complex bus stop example. After all, the difference between them is simply a matter of a slight decrease in the complexity of the reasons to which one is responding. If our cases of interrupted action are similar enough to the central cases to count as reasoning, why aren't cases involving less complex "practical shapes" similar enough to count as reasoning too? Perhaps we could find some principled basis for privileging the former similarity over the latter, but Dancy never specifies exactly how he's understanding the similarity relation at work in the focalist principle, so it's unclear what that basis could be.

In summary, I've outlined the Completed Reasoning Objection to the Aristotelian Thesis and considered two main lines of reply. I've argued that the objection doesn't overextend to rule out the possibility of intentions or beliefs as conclusions, and that Dancy's focalist response doesn't meet the objection and generates further difficulties. I've also offered an explanation for the intuition underlying the objection: it seems that an interruption that prevents an intention from yielding action doesn't amount to incomplete reasoning since one of the central functions of intentions is to allow for the influence of completed reasoning to extend across time.

It's worth noting, however, that not all versions of the Aristotelian Thesis will be vulnerable to this objection. For instance, Philip Clark (2001) argues that actions are the conclusions of practical reasoning in the sense that they are the contents of the intentions formed via practical reasoning. This

\footnotetext{
${ }^{41}$ It has been suggested to me that instead of increasing the complexity of the "practical shape," we could increase the complexity of the means-ends structure, so that, for instance, in the case where I get off at my stop, in order to go to the office, in order to read, etc., I would be acting in light of reasoning. However, it still seems to me that if I do this all out of habit without deliberating - as is pretty much the case with my morning commute at least - then I don't seem to be acting in light of reasoning any more than I was in Dancy's original example, though of course I act for a reason.
} 
view would allow for an action as the conclusion of practical reasoning even when some interference or inability prevents the action from coming about.

There's a question of how well this version of the Aristotelian Thesis squares with what Aristotle said about practical reasoning, but I'm leaving aside the question of how to interpret Aristotle in this paper. ${ }^{42}$ There's also a worry that this view would render the standard Aristotelian contrast between the conclusions of theoretical and practical reasoning - where theoretical reasoning concludes in a belief and practical reasoning concludes in an action - confused, since the conclusion of theoretical reasoning would be an attitude, not its contents (the belief, not the proposition believed) while the conclusion of practical reasoning would be the contents, not the attitude (the action, not the intention). ${ }^{43}$ But, nonetheless, it's worth noting that the objection doesn't target this view. So, this might be a version of the Aristotelian Thesis that the defender of the intentions-as-conclusions view could endorse: practical reasoning concludes in an intention the content of which is an action. I'll set this view aside.

As I mentioned at the start, the intentions-as-conclusions view faces challenges from two directions: from Aristotelians who suggest that the view doesn't extend reasoning far enough practical reasoning must take us all the way to action - and from philosophers who suggest that it extends practical reasoning too far, since practical reasoning can only bring us to beliefs (with normative contents). Let's now turn to some challenges from the other side.

\section{\$2. On Intentions as Conclusions: Raz on Reasoning and Realizations}

Joseph Raz presents an argument against both the Aristotelian Thesis and the intentions-asconclusions view. The argument is meant to "exclude the possibility of intentions as conclusions of reasoning." ${ }^{44}$ The basic idea behind the argument is that reasoning is a transition involving a discovery or realiation - specifically, either a discovery of some conclusion or the discovery of how some conclusion is supported - but since such discoveries or realizations aren't present in cases of alleged reasoning concluding in an action or an intention, we should not hold that reasoning goes that far.

\footnotetext{
42 In addition to the passage quoted in footnote 1 above, it's worth noting that Aristotle says, when discussing practical reasoning in De Motu Animalium (701a10-15; translation from Nussbaum 1978, 40), "whenever someone thinks that every man should take walks, and that he is a man, at once he takes a walk." This suggests something stronger than Clark's view. But, as I said, I'm leaving such questions aside.

${ }^{43}$ For further discussion see Clark 2001 and Dancy 2014.

${ }^{44} \operatorname{Raz} 2015,160$.
} 
At first glance, the argument might seem question-begging, since requiring that reasoning conclude in a discovery or realization might seem to be just another way of saying that reasoning must conclude in a belief - precisely what Raz's opponent denies. But there are two important, subtle differences. First, Raz doesn't take a realization to be a belief; rather, "realization" "refers to an experience: in extreme cases we refer to it as the Eureka moment." ${ }^{45}$ And, second, what one realizes in reasoning, in Raz's view, need not be the conclusion of the reasoning but could instead be how that conclusion is supported:

...reasoning is an activity whose success depends on coming to realise that some items (premises) support others (conclusions). ... Reasoning is a special case of responding to reasons, responding by discovering, by realizing that $\mathrm{C}$, or that $\mathrm{P}$ supports $\mathrm{C}{ }^{46}$

For instance, it could be that one already believes both the premises and the conclusion, and yet through reasoning comes to experience the premises standing in a support relation to the conclusion.

How does Raz's argument then yield the conclusion that intentions cannot be conclusions of reasoning? I think that there are two different ways of reading Raz's argument, each of which has some support in the text. On the first way of reading it, there is something about the cognitive nature of discovery or realization - specifically, that such experiences lead us to beliefs - that commits us to thinking that reasoning must conclude in a belief. Raz writes:

Reasoning ... is an activity that leads to a realization that the conclusion is a well-supported answer to the question one is considering, and this is confirmed by our implicit knowledge of what reasoning is. Given that what one is led to when realizing something is a belief, it follows that the conclusion of reasoning is a belief. ${ }^{47}$

However, it seems that we could grant the point that "what one is led to when realizing something is a belief' but deny that Raz's conclusion follows. Keep in mind that what one may realize in reasoning is that a support relation obtains between premises and conclusion. If we grant that the realizing (the "experience" that isn't identical with belief) leads to a belief, we have to grant that in such cases one comes to believe that a support relation obtains between premises and conclusion. But nothing follows about the relata themselves; it's perfectly compatible with this that neither the premises nor the conclusions are themselves beliefs. (To bring this out, we might think about suppositional reasoning. I might reason from a supposition that $\mathrm{A}$ to a supposition that $\mathrm{B}-$ e.g., supposing the Yankees win

\footnotetext{
${ }^{45} \operatorname{Raz} 2015,159$.

$46 \operatorname{Raz} 2015,159$.

${ }^{47}$ Raz 2015, 159.
} 
the division title, it follows that the Red Sox, who are in the same division, lose the division title - and here I might experience the first supposition supporting the second, and then come to believe that the first supposition supports the second, without these suppositions being beliefs. ${ }^{48}$ ) So, I don't think the argument, so understood, succeeds in showing that the conclusion of reasoning must be a belief.

There is a second way of reading Raz's argument, however, which I think better reflects his main reservations about allowing either actions or intentions as conclusions. On this reading, the argument proceeds in two main steps. First, there is the claim that alleged reasoning to an action or intention must proceed via a belief about what one has conclusive reason to do. ${ }^{49}$ In Raz's view, for any possible line of reasoning, there must be "something amiss, some imperfection" if the reasoner holds onto the relevant premise-states without forming the conclusion-state (for instance, holding on to the belief that $\mathrm{P}$ and the belief that if $\mathrm{P}$ then $\mathrm{Q}$ without believing that $\mathrm{Q}) \cdot{ }^{50}$ Raz notes that there would be something amiss if the premises included a belief that one has conclusive reason to $\phi$ and yet one didn't intend to $\phi^{51}$, but there need be nothing amiss if the premises instead included only a belief that one has merely sufficient reason to $\phi$, since it's perfectly fine to believe one has sufficient reason to $\phi$ and not intend to $\phi$. The second step of the argument then points out that this final stage - the transition from a belief that one has conclusive reason to $\phi$ to one's intending to $\phi$ (or to one's $\phi$-ing) doesn't involve any sort of discovery or realization:

If the reasoning of some people establishes that there is an adequate or a conclusive reason for them to intend, it left nothing (relevant) for them to discover or realize. If they form that

\footnotetext{
${ }^{48}$ I may arrive at a belief in the conditional if the Yankees win the division title, then the Red Sox lose it. But that doesn't affect the point that I reasoned from one supposition to another.

${ }^{49}$ I'll grant this claim for the sake of argument. But it's worth noting that others have challenged it. For instance, Dancy $(2014,11)$ argues that Raz here presents us with a "rather heavy-handed picture of deliberation." And Broome (2013, 263264), while not directing his remarks against Raz's view, considers a case that could be used to challenge it: it seems like good reasoning in a Buridan case to go from the observation that one must eat hay to survive to a decision to eat from the left bale, even though one thinks one has merely sufficient reason to eat from the left bale, since there's equally good reason to eat from the right bale instead. Broome holds that reasoning to the decision to eat from the left bale is good reasoning, even though it doesn't proceed via a belief about what one has conclusive reason to do. And John Schwenkler (2019, esp. Ch. 5) reads Anscombe's case for the Aristotelian Thesis as involving a rejection of this claim.

${ }^{50} \mathrm{Raz} 2015,156-7,146$. This could be challenged. Broome $(2013,219)$ argues that correct reasoning is governed by rational permissions, not rational requirements, and so, at least in some cases, there need be nothing amiss with one holding the premise-attitudes but not the conclusion-attitudes.

${ }^{51}$ Perhaps not, if one also thought that one would $\phi$ regardless of whether one intended to do so. Precise formulations of the anti-akrasia requirement will take such cases into account. (See, for instance, Broome 2013, 170.) We'll return to the significance of this point in $\$ 3$.
} 
Penultimate draft of a paper forthcoming in The Journal of Ethics. Please cite the published version.

intention they do so for a reason, but no realisation leads to that formation, only their prior knowledge that they have reason to intend. ${ }^{52}$

No realizations occur at this last stage. You have already realized everything you need to realize in believing that you have conclusive reason to $\phi$. All that remains is for you to apply that knowledge by forming the relevant intention to act. Since realizations are essential to the reasoning process, and since this last stage doesn't involve any sort of realization, we should think of this last stage as occurring after your reasoning has already concluded. Thus, your reasoning here concludes with the belief that you have conclusive reason to $\phi$, and not with an intention to $\phi$, or with the action of $\phi$ ing.

This argument presents a powerful challenge to defenders of the possibility of practical reasoning concluding in an intention. But I think there is a way to resist the argument. We could agree with Raz's general constraint that, for any possible line of reasoning, there must be "something amiss, some imperfection" with one's having the premise-states and lacking the conclusion-state. But we could hold that instrumental reasoning involving means believed to be necessary satisfies the constraint. Something would be amiss with my intending to go to the party, believing that to do so I must intend to drive up $27^{\text {th }}$ street, and yet not intending to drive up $27^{\text {th }}$ street. ${ }^{53}$ After all, it's standardly thought that there's a rational requirement governing ends and means, just as there's a rational requirement prohibiting akrasia. ${ }^{54}$

But with such instrumental reasoning, it's hard to see why there wouldn't be any realizations involved. By forming an intention to take the necessary means, I would come to realize something, namely how I will achieve my end. Suppose I intend to get to the party, but don't intend to drive up $27^{\text {th }}$ street. At this point, it would be a bit of a mystery to me how I'll get to the party. It's true that I know the general instrumental fact that one won't get to the party without intending to drive up $27^{\text {th }}$. But, lacking an intention to do this (nor trusting that I'll form one at a later time), I would be in the dark about how $I$ would get to the party. But my epistemic situation is significantly improved once I

\footnotetext{
${ }^{52} \operatorname{Raz} 2015,160$. As the quotation indicates, the first step of the argument is stronger than it needs to be, since even if reasoning to an intention to $\phi$ proceeded via a belief that one has adequate reason to $\phi$, we'd still have the problem that there is nothing left to realize.

${ }^{53}$ As we noted in $\$ 1$ above, this line of reasoning concludes in an intention, and it need not proceed via any belief about what one has conclusive reason to do. One could think one has merely sufficient reason to attend the party, or, as we supposed earlier, conclusive reason not to attend.

${ }^{54}$ In another paper (Raz 2005), Raz raises several important doubts about standard understandings of that requirement, but he does hold that those who fail to intend the means believed necessary for their ends thereby exhibit a kind of improper rational functioning, and that would be enough to show that there's "something amiss" or "some imperfection" there.
} 
come to intend the necessary means: now I know how I'll get to the party, whereas before this was a mystery. In short, instrumental reasoning provides an example of reasoning concluding in an intention that allows for the possibility of some realization or discovery.

It's open to Raz to reply that this isn't the relevant kind of realization that reasoning must involve. In my example, I come to discover how I'll get to the party by concluding my instrumental reasoning - that is, by forming the intention to drive up $27^{\text {th }}$ street. But what reasoning requires, he might argue, is that the realization or discovery be the basis for my concluding, rather than something I come to by way of concluding. So understood, the realization of how I'll get to the party would not be of the relevant sort. It comes too late.

My reply would then be to suggest that the relevant realization could occur earlier on. Perhaps my discovery is that I must travel up $27^{\text {th }}$ to get to the party. Or perhaps my discovery is that my intention to go to the party, combined with this instrumental belief, supports my intending to drive up $27^{\text {th }}$ street. Either way, there is a discovery that could be the basis for my concluding.

A possible response to this reply would be for Raz to introduce a parallel version of the original objection. According to the original objection, if a person already believes she has conclusive reason to $\phi$, there is nothing left for her to discover or realize. And so proceeding from a belief that one has conclusive reason to $\phi$ to intending to $\phi$ doesn't involve reasoning. The parallel version would hold that if someone intends to go to the party, and believes driving up $27^{\text {th }}$ street is necessary, and realizes that these attitudes support intending to drive up $27^{\text {th }}$, there is nothing left for them to discover or realize. So, the transition from these attitudes to an intention to drive up $27^{\text {th }}$ street wouldn't involve reasoning.

But if this is Raz's argument, then I think he's presenting too strong of a constraint on reasoning, such that ordinary cases of theoretical reasoning would be ruled out. Consider a modus ponens inference: Suppose I believe that $\mathrm{P}$ and I believe that $\mathrm{P} \rightarrow \mathrm{Q}$, and realize that these attitudes support believing that Q, but I haven't yet come to believe that Q. Raz would have to say that my proceeding from my belief that $\mathrm{P}$ and my belief that $\mathrm{P} \rightarrow \mathrm{Q}$ to the belief that $\mathrm{Q}$ wouldn't count as reasoning, since there's no realization or discovery involved in so proceeding. That's implausible.

Moreover, it's unclear why we should expect further realizations at this point in the reasoning process. What I need to do is to make the revisions in attitude called for by realizations already made. The point here relates to Lewis Carroll's famous discussion of Achilles and the Tortoise. ${ }^{55}$ The

55 Carroll 1895. 
Tortoise believes that $\mathrm{P}$, and that $\mathrm{P} \rightarrow \mathrm{Q}$, but, skeptically, doesn't go on to believe that $\mathrm{Q}$. Achilles makes the mistake of thinking that there's some further premise that the Tortoise needs, proposing that the Tortoise add to his stock of premises the belief that if $P$ and $P \rightarrow Q$, then $Q$. The Tortoise happily adds the premise, but resumes his skepticism, refusing to come to believe that Q. The Tortoise's problem wasn't that he was missing some premise; rather, his problem was that he refused to apply modus ponens to the premises he already had. That application of modus ponens need not involve any new discovery or realization that would be the basis for his coming to believe that Q. But it would enable him to conclude his reasoning.

I've used an example of modus ponens reasoning to make this point, but the point seems to generalize: there can be stages of reasoning which don't involve new realizations, but instead involve revising attitudes in ways called for by realizations already made. As Gilbert Harman observes, there are

... two possible phases in reasoning. On the one hand there is often a process of reflection in which one thinks about one's beliefs, plans, desires, etc. and envisions various possibilities in more or less detail. On the other hand there is the actual revising of one's view, which may or may not follow such a reflection. ${ }^{56}$

The changes made in the second phase would count as part of the agent's reasoning, in Harman's view. However, we shouldn't expect further realizations or discoveries in this phase. Those would instead occur in the first phase, as part of the process of reflection. In the second phase, one makes those revisions called for by realizations made in the first phase. Raz's mistake is that he assumes that all phases of reasoning must involve realizations. But, as we've seen, even in ordinary modus ponens reasoning, there's a possible stage of reasoning which need not involve any further discoveries or realizations.

\section{\$3. On Beliefs as Conclusions: The Worry about "Practicality"}

I argued in the previous section that we have resources to resist Raz's argument against the possibility of intentions as conclusions of reasoning. I haven't argued in this paper that practical reasoning must conclude in an intention. Instead, I'm defending a more permissive, disjunctive view, where practical reasoning could conclude in either a belief or an intention. I won't have space for anything close to a full defense of this view, but I do want to motivate its plausibility by responding to a central source of

\footnotetext{
56 Harman 1986, 2.
} 
Penultimate draft of a paper forthcoming in The Journal of Ethics. Please cite the published version.

resistance to the idea that beliefs are possible conclusions of practical reasoning. The source of resistance is that allowing for beliefs as conclusions wouldn't make practical reasoning sufficiently "practical." More precisely, the idea is that practical reasoning must be practical not only in its subject matter but also in its upshot, and beliefs are simply too far removed from intention and action to qualify as genuinely practical conclusions. So, reasoning concluding in beliefs cannot qualify as genuinely practical reasoning. Here's how Maria Alvarez puts this complaint about reasoning concluding in beliefs:

...such a conclusion is not practical, for one may indeed conclude this but not go on to decide to or intend to act; nor, of course, to act. Because of this, it is not clear that that would be a piece of practical reasoning. ${ }^{57}$

A genuinely practical conclusion, in her view, must involve an intention to act or action itself. ${ }^{58}$

There are several responses one could give to this line of argument. One would be to argue that the dispute over the conclusion of practical reasoning is threatening to become a merely verbal dispute about what we call "practical." Another, related, response would be to argue that limiting the correct application of "practical" to reasoning concluding in an intention or action might not make for a theoretically interesting way to divide up kinds of reasoning. After all, my reasoning now about how I should have commuted to work yesterday might not differ all that much from my reasoning now about how I should commute to work tomorrow, but only the latter kind of reasoning would be a candidate for "genuinely practical reasoning," since only the latter kind of reasoning could result in an intention or action. But all other aspects of the reasoning - my going through the pros and cons of various routes, weighing competing values against one another, etc. - might be exactly the same, raising the question of why it would be important to designate a special kind of reasoning - practical reasoning, properly so called - that would apply to one line of reasoning but not the other. ${ }^{59}$ However, I want to put such concerns aside, and assume that we do have good theoretical motivations for isolating a specific kind of reasoning that's sufficiently close to action such that it deserves to be called

\footnotetext{
57 Alvarez 2010, 370, emphasis in original.

58 See also Fink 2013, as well as Fernandez's (2016, 869-871) related discussion of the "practical problem" (modeled on Smith's (1994) "moral problem") according to which a theory of practical reasoning must accommodate both the fact that practical reasoning is subject to assessment by objective standards of correctness (what he calls "Objectivity") and the fact that practical reasoning bears a regular connection to action (what he calls "Practicality"). In his view, the Aristotelian Thesis, which "entails that an agent's practical reasoning has not concluded until she acts" (p. 873), is able to accommodate both Objectivity and Practicality, whereas a view which has practical reasoning conclude in belief is unable to accommodate Practicality.

59 Likewise, my reasoning about how you should commute to work tomorrow - suppose we live and work in the same buildings - might not differ from my reasoning about how I should commute to work tomorrow, but only the latter would be a candidate for genuinely practical reasoning.
} 
Penultimate draft of a paper forthcoming in The Journal of Ethics. Please cite the published version.

genuinely "practical" reasoning. Instead, I'll argue that beliefs can be as close to action as intentions are. In other words, if we allow for intentions as possible conclusions of practical reasoning, we don't have good grounds for disallowing beliefs with normative contents as possible conclusions of practical reasoning, since those beliefs may be as practically relevant as those intentions.

Let's start by thinking about the practical relevance of concluding intentions. Suppose I'm reasoning about what to buy to cook dinner tonight, and I reason to a decision to buy a can of tomatoes. This concluding intention could be the basis for further planning, as I figure out how to find the tomato can aisle in the grocery store. It could also be the basis for further choice. I might find myself needing to select one of many equally good cans from the shelf. Unlike my attempt to find the tomato can aisle in the grocery store, my selecting one of the cans doesn't seem to involve any further reasoning on my part, though it is guided by my intention to buy a can. ${ }^{60}$ Additionally, once deciding upon a particular can, there are various ways I could go about getting the can (e.g., moving my arm in various particular ways) that don't involve any reasoning or decision.

But the question now would be why a belief with the appropriate normative content couldn't play that same practical role. Couldn't a belief that I ought to buy a can of tomatoes be the basis for further instrumental reasoning? Couldn't it guide further choice, as when I have to select one of many equally good cans from the shelf? Why not allow that a concluding belief could play the same practical role as a concluding intention? ${ }^{61}$

\footnotetext{
${ }^{60}$ As Sarah Paul $(2013$, 296) observes, the selection of one of many equally good means - taking one of fifteen pens in the drawer to sign the contract, in her example - requires "no further judgment of choiceworthiness" and so shouldn't be understood as involving an exercise of reasoning. I agree with Paul on this point, though it isn't necessary for the argument in this section. It's worth noting, however, that the point is controversial, even among Aristotelians. Anton Ford (2016, 149) has argued that "if reckoning with particulars is excluded from practical reasoning, then practical reasoning cannot do its characteristic work: it cannot answer the question what to do." In contrast, Jonathan Dancy $(2018,30-33)$ has insisted on what he calls "the Prichard Point": the idea that practical reasoning will only favor acting in a certain way (e.g., grabbing a pen) rather than a particular act (e.g., my grabbing of, say, the particular pen on the far left). In Dancy's view, practical reasoning could do its characteristic work without reckoning with particulars. Further discussion of this issue would take us too far afield.

${ }^{61} \operatorname{Raz}(2015,155-156)$ also argues that beliefs with normative contents can be practically relevant by themselves - that is, not in virtue of associated intentions. He gives the example of someone who believes that he ought not be disloyal, but never forms an intention not to be disloyal. Indeed, the person is never tempted toward disloyalty - the thought of disloyalty never occurs to him - and so there's no need for him to form such an intention. But, Raz argues, the belief that he ought not be disloyal is relevant to how he acts. I worry that Raz's argument here confuses resolutions with ordinary intentions. We might follow Holton $(2009,11)$ in understanding resolutions as intentions supported by second-order intentions not to be derailed in executing that first-order intention. It's plausible that the person never tempted toward disloyalty has no need for resolutions. But it doesn't follow that he has no need for a (first-order) intention not to be disloyal. (The intention not to be disloyal would be a general one - what Michael Bratman (2007, 283-6) refers to as a "policy." But it would still qualify as an intention.) Despite my worries about this particular example (and a second example, which would be too complicated to discuss here) I think Raz's strategy here is on the right track. The argument in the text below will help dislodge one basis for thinking that beliefs with normative contents can be practically relevant only through associated intentions.
} 
Penultimate draft of a paper forthcoming in The Journal of Ethics. Please cite the published version.

In response to these questions, the critic of the beliefs-as-conclusions view likely won't argue for the psychological impossibility of my proceeding directly from a belief that I ought to buy a can of tomatoes to a decision to pick out a particular can - say, the one on the left. Such claims about the impossibility of psychological transitions are difficult to substantiate. But they're also unnecessary for the argument. The critic could instead argue that a fully rational agent couldn't transition from the concluding belief directly to the decision to take the can on the left. Instead, the critic might argue, when one is fully rational, one's belief that one ought to buy a can of tomatoes would be a rational basis for an intention to buy a can of tomatoes and that intention would be a rational basis for the downstream decision to take the can on the left. It wouldn't be rational for one to proceed directly from the belief to the decision to take the can on the left - one needs an intermediate intention with a content that matches the belief (here, an intention to buy a can of tomatoes). Let's call this the “intermediate matching intention." If that's right, we can isolate a way in which a concluding belief isn't "practical": a belief cannot directly be the basis for downstream decision. I must first engage in so-called enkratic reasoning - proceeding from the belief that I ought to $\phi$ to an intention to $\phi-$ before I have an attitude (the intermediate matching intention) that could be a basis for the downstream decision to take the can on the left.

But why think an intermediate matching intention is required? Support for this is naturally found by appealing to the enkratic requirement - the rational requirement that, roughly, forbids me from both believing I ought to $\phi$ and not intending to $\phi$. There would, one might argue, be some rational mistake if I were to believe I ought to buy a can of tomatoes and not also intend to buy one. If that's right, it could never be rational to proceed directly from the belief that I ought to $\phi$ to a downstream decision without forming the intermediate matching intention. A failure to form the intermediate matching intention (while still holding onto the belief that I ought to $\phi$ ) would involve violating a rational requirement, and so proceeding this way is incompatible with my being fully rational.

This line of argument might lead us to deny that concluding beliefs can have the same practical relevance as concluding intentions. We might think that intentions provide a rational basis for downstream decisions leading to action, whereas beliefs only appear to do this: really it's the intermediate matching intention that does the work. But I think this line of argument is ultimately mistaken, and that beliefs can rationally have the same direct downstream practical relevance that 
intentions have. We can see the mistake in the argument when we see the ways in which the version of the enkratic requirement mentioned above is roughly formulated.

Precise formulations of the enkratic requirement hold that the requirement is in place only when one believes that an intention to $\phi$ is necessary for doing what one believes one ought to do. For instance, as John Broome and others have noted, in a case where one would $\phi$ automatically, and so there would be no need to intend to $\phi$, it would be rationally permissible for one to both believe one ought to $\phi$ and not intend to $\phi .^{62}$ In Broome's official formulation of the requirement, the requirement holds only when I believe that my $\phi$-ing is "up to me" in the sense that I believe both that if I were to intend to $\phi$, then I would $\phi$, and that if I were not to intend to $\phi$, then I would not $\phi .{ }^{63}$

But if that's right, there are cases where one could proceed, without enkratic irrationality, from a belief about what one ought to do to a downstream decision without having an intermediate matching intention. One clear example would be beliefs with normative contents that are disjunctive (e.g., "I ought to study either philosophy or history", "I ought to buy either garlic or ginger.”) In such cases, it would be highly unusual for me to have the belief that an intermediate matching intention is necessary for doing what I ought to do. I know, for instance, that I can buy either garlic or ginger without intending to buy either garlic or ginger. I know that a mere intention to buy ginger would lead me to buy ginger, and that would be a way of doing what I ought to do. So, rationality doesn't require that my belief be accompanied by a matching intention. So, there's no reason to think that proceeding directly from that normative belief to a further decision, without an intermediate matching intention, need involve irrationality. (Plausibly, there are other non-disjunctive examples of this as well. I might rationally proceed from a belief that I ought to do something fun this evening to an intention to get out the board games, without proceeding via an intention to do something fun this evening. After all, I know that such an intention isn't necessary for my doing something fun this evening.)

\footnotetext{
${ }^{62}$ See Broome 2013, 171. Kieran Setiya (2007, 667-668) makes a point about "automatic means" along these lines in connection with instrumental rationality, but the same point would carry over to the enkratic requirement.

${ }^{63}$ Here is Broome's official formulation of the requirement:

Enkrasia: Rationality requires of $\mathrm{N}$ that, if

(1) $\mathrm{N}$ believes at $\mathrm{t}$ that she herself ought that $p$, and if

(2) $\mathrm{N}$ believes at $\mathrm{t}$ that, if she herself were then to intend that $p$, because of that, $p$ would be so, and if

(3) $\mathrm{N}$ believes at that, if she herself were not then to intend that $p$, because of that, $p$ would not be so, then

(4) $\mathrm{N}$ intends at that $p$. (Broome 2013, 170)
} 
If my argument is along the right track, then beliefs can play the same practical role as intentions. Both can be the basis for further planning and choice leading to action. ${ }^{64}$ So, if we allow for intentions to count as genuine conclusions of practical reasoning in virtue of their practical role, we don't have principled grounds for disallowing beliefs with normative contents as conclusions of practical reasoning as well, since they can play this very same practical role.

The argument so far has worked with a certain understanding of the practical role of intentions, specifically that they guide us to action by being a rational basis for further reasoning and decision. I've argued that some beliefs can play that same practical role, and so there's no principled grounds for disallowing beliefs as possible conclusions of practical reasoning. But it may be that critics of the beliefs-as-conclusions view have a more ambitious understanding of the practical role of intentions, specifically that they can always directly cause actions without further reasoning and choice. One critic of the beliefs-as-conclusions view, Julian Fink, seems to hold this view:

Intentions are mental states which have the propensity to directly cause you to do what you intend. In addition, an intention does not seem to require further reasoning to cause you to act. $^{65}$

However, I don't think this is the correct understanding of the practical role of intentions. Many of our intentions require additional sub-planning before we're in a position to act. It's possible, for instance, for me to reason to an intention to buy a house, or to an intention to work as a professional art historian, without being in a position to do what I've intended to do without further reasoning. Even an ordinary intention to do something later today in a different location might require me to first reason about to how get there, in order to put myself in position to perform the intended action. If Fink's ambitious account of the practical role of intentions were correct, we might be able to argue that concluding intentions have a practicality not shared by concluding beliefs with normative contents. But I doubt that it is correct. And on our more modest account of the practical role of intentions, it's not clear that we have good grounds for disallowing beliefs as possible conclusions of practical reasoning.

\footnotetext{
64 The argument in the text has focused on an example which shows how beliefs could be the basis for further choice. But I also think beliefs could be the basis for further reasoning. Suppose I believe I ought to buy something to add some heat to dinner, and I believe that the only item in the store that would add heat is the red pepper flakes, and so I form an intention to buy the red pepper flakes. There may be a similar temptation to think that this process is rational only if I first form an intention to add some heat to dinner. I don't think this is right. I might, reasonably, think that such an intention isn't necessary for doing what I believe I ought to do, in which case there would be no violation of the enkratic requirement in proceeding this way. Proceeding in this way is both possible and rational.

${ }^{65}$ Fink 2013, 473.
} 


\section{\$4. Conclusion}

In this paper, I've argued that the Completed Reasoning Objection to the Aristotelian Thesis doesn't overextend to rule out the possibility of intentions or beliefs as conclusions of practical reasoning. I've also argued that Dancy's "focalist" response doesn't meet the objection and generates further difficulties. In defense of the possibility of intentions as conclusions, I've argued that we can resist Raz's realization argument. While it's plausible to think that reasoning involves realizations, it's too strong to insist that all stages of reasoning do so. That would make trouble for ordinary theoretical reasoning. It's better to follow Harman and others in thinking that part of reasoning involves making revisions in one's attitudes in light of realizations made at an earlier stage. Lastly, in response to the "practicality" objection to the beliefs-as-conclusions view, I've argued that if we think of the practical role of concluding intentions - their role in guiding further reasoning and choice leading to action we don't have good grounds for disallowing beliefs as conclusions of practical reasoning, since beliefs could sometimes share this practical role.

I haven't considered all of the arguments involved in the complicated debate over the conclusion of practical reasoning, nor could I hope to do so here. Nor have I given anything close to a full defense of the Disjunctive View - that is, the view that practical reasoning could conclude in either an intention or a belief with normative content. But I hope to have cleared away some obstacles to accepting the Disjunctive View, and perhaps also put us in a position to see some advantages of it. In particular, the Disjunctive View accommodates many cases that have intuitively struck philosophers as cases of practical reasoning. (In contrast, the view that practical reasoning concludes only in beliefs will struggle to explain the cases of instrumental reasoning we considered in \$1.) Additionally, the Disjunctive View better accommodates the point, made in $\$ 3$, that belief and intention can play the same practical role. (In contrast, the view that practical reasoning concludes only in intention will seem arbitrary, given that concluding beliefs can play the same practical role as concluding intentions.) But, of course, much more would need to be said in favor of the Disjunctive View. I hope only to have done enough to suggest that this would be a fruitful line of inquiry. ${ }^{66}$

\footnotetext{
66 This paper began as a paper on Raz's view of the conclusion of practical reasoning, given at a conference in Joseph's honor at the Law School at King's College London. I'm very grateful to Jay Wallace, who commented on that paper, and to Joseph, whose first question amounted to a second commentary on the paper. I'll learned a lot, but probably still not enough, from their comments. Thanks also to Sam Scheffler, who suggested to me after the talk that I frame the paper as a defense of the Disjunctive View. More recently, I presented the paper to a wonderful audience at the University of Notre Dame. Thanks especially to Robert Audi and Ted Warfield for helpful comments and discussions. I'm also grateful for the constructive comments of several anonymous reviewers.
} 


\section{Works Cited}

Alvarez, M., 2010, "Reasons for Action and Practical Reasoning” Ratio 23(4): 355-373.

Anscombe, E., 1957, Intention, Oxford: Basil Blackwell.

Aristotle, 1999, Nichomachean Ethics, Second Edition (trans. Terrence Irwin), Cambridge: Hackett Publishing.

Audi, R., 2006, Practical Reasoning and Ethical Decision, London: Routledge.

Brandom, R., 1994, Making it Explicit, Cambridge, MA: Harvard University Press.

Bratman, M., 1987, Intentions, Plans, and Practical Reason, Cambridge: Harvard University Press.

Bratman, M., 2007. Structures of Agency: Essays, Oxford :Oxford University Press.

Broome, J., 2002, "Practical Reasoning" in J. Bermudez and A. Millar (eds.) Reason and Nature: Essays in the Theory of Rationality, Oxford: Clarendon Press.

Broome, J., 2013, Rationality Through Reasoning, Malden, MA: Wiley-Blackwell.

Brunero, J., 2020, Instrumental Rationality: The Normativity of Means-Ends Coherence, Oxford: Oxford University Press.

Carroll, L., 1895, "What The Tortoise Said to Achilles" Mind 4 (14): 278-80.

Charles, D., 1984, Aristotle's Philosophy of Action, Ithaca: Cornell University Press.

Clark, P., 2001, “The Act as Conclusion” Canadian Journal of Philosopby 31(4): 481-505.

Dancy, J., 2014, "From Thought to Action" in R. Shafer-Landau (ed.) Oxford Studies in Metaethics,

Vol. 9, Oxford: Oxford University Press.

Dancy, J., 2018, Practical Shape: A Theory of Practical Reasoning, Oxford: Oxford University Press.

Fernandez, P., 2016, "Practical Reasoning: Where The Action Is" Ethics 126 (4): 869 - 900.

Fink, J., 2013, “What is Correct Practical Reasoning?” Acta Analytica 28(4): 471-482.

Ford, A., 2016, “On What Is in Front of Your Nose” Philosophical Topics 44(1): 141-161.

Harman, G., 1986, Change in View, Cambridge, MA: MIT Press.

Holton, R., 2009. Willing, Wanting, Waiting, Oxford: Oxford University Press.

Korsgaard, C., 2009, Self-Constitution: Agency, Identity and Integrity, Oxford: Oxford University Press.

McDowell, J., 2010, "What is the Content of an Intention in Action" Ratio 23: 415-432.

McDowell, J., 2011, "Some Remarks on Intention in Action" The Amberst Lecture in Philosophy, 6, 1 18.

McHugh, C. and J. Way, 2018, "What is Reasoning?” Mind 127(505):167-196.

Nussbaum, M., 1978, Aristotle's De Motu Animalium, Princeton: Princeton University Press.

Paul, S., 2013, "The Conclusion of Practical Reasoning: The Shadow Between Idea and Act"

Canadian Journal of Philosophy 43(3): 287-302.

Raz, J., (ed.), 1978, Practical Reasoning, Oxford: Oxford University Press.

Raz, J., 2005, "The Myth of Instrumental Rationality" Journal of Ethics and Social Philosophy, 1(1): 1-28.

Raz, J., 2011a, “On Practical Reasoning” in From Normativity to Responsibility, Oxford: Oxford

University Press, 103-105.

Raz, J., 2011b, “Practical Reasoning” in From Normativity to Responsibility, Oxford: Oxford

University Press, 129-140.

Raz, J., 2015, "Normativity: The Place of Reasoning” Philosophical Issues: A Supplement to Noûs, 25,

Normativity: 144-164.

Schwenkler, J. and B. Marušić, "Intending is Believing: A Defense of Strong Cognitivism" Analytic

Philosophy 59(3), 309-340.

Schwenkler, J., Anscombe's Intention: A Guide, Oxford: Oxford University Press.

Searle, J., 2001, Rationality in Action, Cambridge, MA: MIT Press. 
Sellars, W., 1966, "Thought and Action" in Freedom and Determinism, Keith Lehrer (ed.), New York: Random House, pp. 105-139.

Setiya, K., 2007, “Cognitivism about Instrumental Reason” Ethics 117(4): 649-673.

Setiya, K., 2018, "Intention" The Stanford Encyclopedia of Philosopby (Fall 2018 Edition), Edward N. Zalta (ed.), URL $=<$ https:// plato.stanford.edu/achives/fall2018/entries/intention/ >

Shah, N., 2008, “How Action Governs Intention” Philosophers' Imprint 8(5): 1-19.

Silverstein, M., 2017, "Ethics and Practical Reasoning” Ethics 127: 353-382.

Smith, M., 1994, The Moral Problem, Oxford: Blackwell Publishing.

Tenenbaum, S., 2007, "The Conclusion of Practical Reason" in S. Tenenbaum (ed.) New Trends in Philosophy: Moral Psychology, Amsterdam: Rodopi, 323-343.

Velleman, D., 1989, Practical Reflection, Princeton: Princeton University Press.

Velleman, D., 2000, The Possibility of Practical Reason, Oxford: Oxford University Press.

Vogler, C., 2002, Reasonably Vicious, Cambridge, MA: Cambridge University Press.

Wallace, R. J., 2001, “Normativity, Commitment, and Instrumental Reason” Philosophers' Imprint 1(4): $1-26$.

Wiland, E., 2013, "In the Beginning was the Doing: The Premises of the Practical Syllogism" Canadian Journal of Philosophy 43(3): 303-321.

Williams, B., 1981, "Internal and External Reasons" in Moral Luck, Cambridge: Cambridge University Press, 101-113. 